\title{
Spatial inequality in municipal solid waste disposal across regions in developing countries
}

\author{
*C. C. Chen \\ Graduate Institute of Environmental Management, Nanhua University, Taiwan
}

Received 10 December 2009; $\quad$ revised 15 March 2010; accepted 10 May 2010; availab(भIRnline 1 June 2010

\begin{abstract}
The regional inequalities in socio-economical characteristics such as income, population density, age composition, unemployment rate and the education level may bring about variation in waste generation, recycling and collection. Using environmental Kuznets curve, the factors affecting municipal solid waste disposal are examined. The results demonstrate that an inverted $\mathrm{N}$-shaped curve executes on municipal solid waste disposal for all regions. As personal disposable income increases, per capita municipal solid waste disposed firstly declines, then grows at the second stage and finally decreases again. All the explanatory variables including economic factors, social characteristics and geographical barriers are found to influence municipal solid waste disposal significantly. Each person increase in population density leads to an increase in municipal solid waste disposed by approximately $1.17 \times 10^{-4} \mathrm{~kg} /$ day. Each percent increase in age composition results in a decrease in municipal solid waste disposed by approximately $0.0224 \mathrm{~kg} /$ day; in the unemployment rate causes a decrease of $0.0901 \mathrm{~kg} /$ day and in the education level results in a decrease of $0.01556 \mathrm{~kg} /$ day. In general, municipal solid waste disposal starts to increase at the first turning point of personal disposable income NT\$198,000 (about US\$ 6,280) and to decrease at the second point of NT\$ 389,000 (about US\$ 12,350) for all regions (pooled data). The rural regions, however, cannot support the inverted Nshaped curve by the 'reduced form' while urban regions have a significant outcome. This result implies that income can only explain a portion of variation while other social and geographical factors contribute a lot to identify the variation in municipal solid waste disposal between urban and rural regions.
\end{abstract}

Keywords: Environmental Kuznets curve; Municipal solid waste; Recycling behavior; Turning point; Waste disposal; Waste generation

\section{INTRODUCTION}

The hypothesis of the environmental Kuznets curve (EKC) claims that economic development is inevitably accompanied with pollution at the beginning stage, but eventually the pollution can be controlled and improved by its economic growth. The EKC represents a statistical connection of some environmental degradation in terms of environmental indicators with income levels. It provides a systematic regularity over the past although some researchers criticize that past empirical analyses leave much debating and are lacking of prediction (Koop and Tole, 1999). A great number of literature have examined the existence of the EKC in a variety of applications including $\mathrm{SO}_{x}, \mathrm{NO}_{x}, \mathrm{CO}_{2}$, water pollutants, etc. (Kahn, 1998; Skonhoft and Solem, 2001; Stern and Common, 2001; Harbaugh et al., 2002; Merlevede et al. 2006; Vinodhini and Narayanan, 2008).

*Corresponding Author Email: ccchen@mail.nhu.edu.tw Tel.IFax: +5242 7112
Dinda (2004) and Copeland and Taylor (2004) have made a critical survey on the issue in association with the EKC. Kearsley and Riddel (2010) examine the role of international trade in shaping the EKC relationship by estimating seven pollutants and find little evidence to support the shifting of polluting industries to lowdeveloped countries. Torras and Boyce (1998) prove the significant existence of the EKC for air pollutants and show that sulphur dioxide and smoke peak at per capita income in the neighborhood of US $\$ 4000$. The empirical study of Kahn (1998) also confirms such an inverted U-shaped relationship between vehicle emissions and median household income. Galeotti and Lanza (2005) find that an EKC is proved to be an adequate choice for $\mathrm{CO}_{2}$ emissions by examining the data from 1971 to 1995 for 108 countries. Friedl and Getzner (2003) find that an N-shaped EKC significantly fit for $\mathrm{CO}_{2}$ emission in Austria. Merlevede et al. (2006) 
incorporate the variable of the firm size into the standard EKC model in a reduced form regression to test the existence of the EKC phenomenon. On the contrary, many researchers can not find a significant support for such an inverted U-shaped curve. Skonhoft and Solem (2001) examine the relationship between the relative amount of wilderness land (wilderness land as a fraction of the total area within each county) and the level of economic activity (measured by income per capita) and give no support for any EKC relationship.

The hypothesis of the EKC postulates a relationship between economic development and environmental degradation based on a global basis and it may fail when it is applied to regional economy that differs in industrial structure and urbanization. In addition to income inequality, the environmental quality and social characteristics also vary across regions. In urban regions, households have higher levels of economic development with more service industry and citizens are more educated with increased environmental awareness. On the contrary, people gain less education levels in rural regions. Most of households rely on farming or manufacturing industries and their socio-economical status is lower in rural regions. Until now, very few researchers focused on the spatial inequality and examined the factors affecting municipal solid waste (MSW) disposal (waste generation minus waste recycling) across regions by applying the EKC theories. For example, some researchers employ life cycle assessment (LCA) technique to analyze the impacts arising from the three different waste treatment technologies, including sanitary landfill, incineration and gasification-pyrolysis of the waste treatment technologies (e.g. Zaman, 2010). Pattnaik and Reddy (2010) assess the performance of MSW management practice in developing countries and some shortcomings are found in the existing MSW management practices. They conclude that a holistic approach on waste management should be implemented by collecting the segregated waste at source, characterization and processing the waste for producing value added products. Waste generation and recycling are strongly considered to relate with consumption and income that can be partly explained by the socio-economical factors (Ogundrian and Afolabi, 2008). Very few, however, focus on this issue from the socio-economical perspective. Furthermore, the determination of turning points in the EKC can help policy makers to design an appropriate environmental policy leading the society towards a sustainable economy according the status of social development. Therefore, this research follows 3 objectives: (1) to test whether an EKC for MSW disposed exists across regions or not, (2) to determine the turning points in the EKC and (3) to examine the factors other than the income variable in analyzing regional inequality of waste disposal. In this research, six separated administrative regions are selected as samples for this study. Among these regions, Taipei Municipality, Taichung Municipality and Kaohsiung Municipality are denoted as urban regions and Yilan County, Hualien County and Taitung County as the rural regions. Taipei Municipality, located in north Taiwan is the capital of Taiwan and has the highest per capita income. Taichung Municipality has the highest income in middle Taiwan, and Kaohsiung Municipality is an industrial city with the highest income in South Taiwan. The three municipalities are located in the western part of Taiwan that is composed of plains, basins and foothills and neighboring to seashores (Fig. 1). On the contrary, the other three counties represents rural regions located in eastern Taiwan and are isolated by geographical barrier of the central mountains that are mostly forested with more than two hundred peaks over 3,000 $\mathrm{m}$ and divide Taiwan Island into two parts (Fig. 1). All the data are provided by DGBAS (2008) covering the period 1998-2008. The data processing and regression analysis were done at Nanhua University in Taiwan during 20009-2010.

\section{MATERIALSAND METHODS}

In this research, a multiple regression model is developed to quantify the relationship between several factors (seen as independent variables) and MSW disposed (as the dependent variable), expressed as

$w_{i t}=\alpha_{0}+\alpha_{1} I_{i t}+\alpha_{2} I_{i t}^{2}+\alpha_{3} I_{i t}^{3}+\alpha_{4}$ popd $_{i t}+$

$\alpha_{5}$ old $_{i t}+\alpha_{6}$ unemp $_{i t}+\alpha_{7} e d u_{i t}+\alpha_{8}$ dum $_{i t}+\varepsilon_{i t}$

where $w$ refers to per capita MSW disposed, $I$ personal disposable income, popd population density, old age composition, unemp unemployment rate, edu the education level, and dum a dummy variable: 0 for urban regions and 1 for rural regions. The subscript $i$ denotes the region and $t$ represents time. The error term is assumed to be identically, independently distributed over a normal distribution with zero mean. In model (1), personal disposable income works as the explanatory variable, which can be seen as the key 


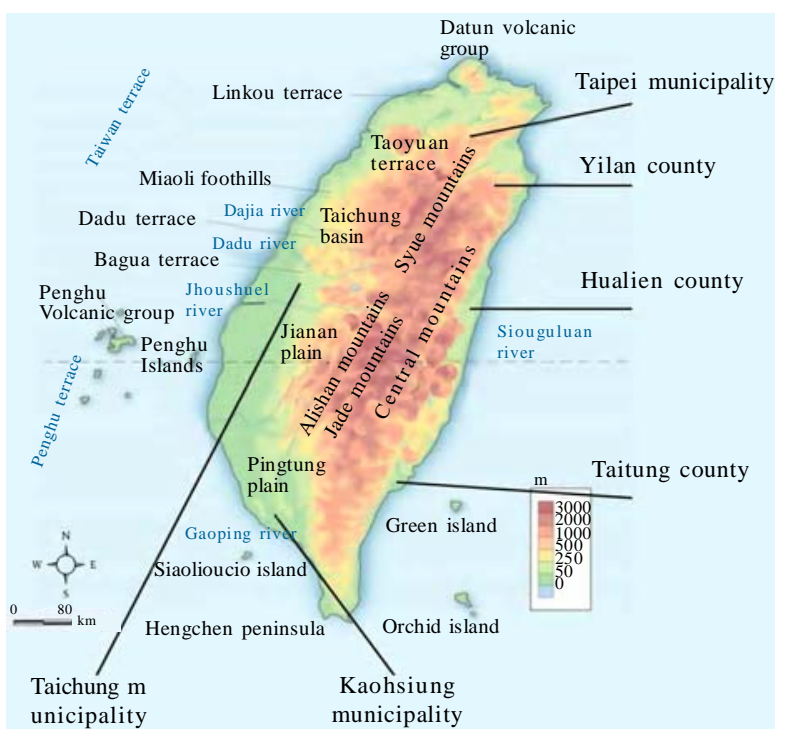

Fig 1: The map of Taiwan

variable of interest in an empirical investigation on the environmental Kuznets curve.

\section{The development of model}

Municipal solid waste for final disposal $W_{f}$ either by landfilling or incineration methods equals to MSW generated $W_{g}$ minus waste recycled $W_{r}$, i.e.

$W_{f}=W_{g}-W_{r}$

The quantity of MSW generation is generally accompanied with consumption level and consumption patterns by the households in the society. Intuitively households with higher income may consume more products/services and thus generate more MSW. A good consumption pattern such as green consumption (an effective tool to tackle MSW problem even though a detailed planning has not yet in practice) may, however, provide a positive force to mitigate environmental impacts through the choice of less environmentally harmful products (Ebreo et al., 1999). Consumption pattern is associated with household behaviors that affect MSW management significantly through their involvement and participation in affecting MSW management (Salhofer and Isaac, 2002; Tonglet et al., 2004; Mattson et al., 2003; McDonald and Oates 2003; Williams and Kelly, 2003). A great number of researchers attempt to explore the determinants of pro-environmental behaviors and suggest that the socio-economic status plays a vital role (e.g. Bickerstaff and Walker, 2001; Teisl et al., 2002; Bamberg, 2003; Iwata, 2002) in consumer preferences and their consequent purchase for green products. Without public engagement (The public may play a role as purchasers and users of goods, as a voluntary recycler and as educators to encourage other in engaging green consumption), waste generation may keep growing. In this study, MSW generation is, in general, determined by income, the education level, unemployment rate in addition to population (or number of households), i.e.

$W_{g}=f_{g}(I$, edu, unemp, $P)$

Where, $P$ represents population.

In contrast, the quantity of MSW recycling also depends on a variety of social characteristics. Some researchers find that recycling behaviors are positively affected by environmental knowledge (Bell et al., 2001). Education plays a vital role in producing more environmentally behaviors such as green consumption and recycling behaviors. It can expand understanding, enhance skills and knowledge and motivate society towards sustainable development. The empirical study of Kotchen and Moore (2007) finds the evidence to support that environmentally concerned consumers may engage in voluntary restraint by consuming less electricity. Ewing (2001) and Scott (1999) suggest that old people are found to be more participated in recycling behaviors to a larger extent than the young, but Werner 
and Makela (1998) finds no significant relationship between age and recycling. Other researchers find that the connection between environmental education and its effect on the environmental system has strong support for the achievement of sustainability. Waste collectors/recyclers can effectively improve recycling performance through successful education and rising awareness. Thus, MSW recycling is expressed as

$W_{r}=f_{r}(I, e d u$, old,$P)$

In addition to socio-economical characteristics, the present study hypothesizes that urbanization may improve living standards and thus lead to the quantity change in waste generation and recycling. In line with the above discussion, MSW disposal is hypothesized to be determined by economic factor (income), social characteristics (the education level, the age composition of the society and unemployment rate) and geographical factor (population density and urbanization of the regions). Integrating Eqs. 2-4 and incorporating geographical factors into Eq. 2 yields:

$W_{f}=f_{g}(I, e d u$, unemp, old,$P$, popd, dum $)$

Dividing by population $P$ on both sides of Eq. (5) gets

$w=f(I$, edu , unemp, old, popd, dum $)$

Thus, the multiple regression model of Eq. 1 is obtained.

\section{The data}

In order to examine the determinants accounting for MSW disposal between urban regions and rural regions, the data of the MSW disposed, personal disposable income, population density, age composition, unemployment rate and the education level is provided by DGBAS (2008) covering the period 1998-2008. Personal disposable income $I$ is measured in terms of NT\$ per capita per year and population density popd is measured by number of residents per square kilometer. The eldness index is used as the proxy variable of age composition old, where the eldness index is defined as ratio of the number of the aged (65 years old or older) to the children (below 14 years old). The education level $e d u$ is measured by the proportion rate of the citizens who graduate from college or higher levels.

\section{RESULTS AND DISCUSSION}

The MSW disposed in the six regions are listed in Fig. 2, in the unit of $\mathrm{kg}$ per person per day. The data indicates that per capita MSW disposed decreases over time as both the population and economical income grow in the past few decades in Taiwan. Table 1 reports summary statistics for the data. Comparing these statistics of urban regions with rural regions reveals that there is a large difference in income I MSW waste disposed $w$, the population density popd, age composition old, unemployment rate unemp and education levels edu between the two regions. The three counties in the rural regions have the highest shares of families living under the poverty line in 2008 with the lowest mean household income while the three municipalities in the urban regions have more income and are wealthier. Urban regions in general have higher income levels and education levels (Table 1) that are seen as primary factors to affect MSW generation and sorting performance. The quality of the data are believed to be reliable and to yield no bias in the estimation results since the publication of this edited statistical data is run by the government and has been lasted for many years. The spatial inequality of waste disposal will be examined and discussed in relation with socio-economical factors and geographical characteristics in the following sections.

Two forms of model (1) are estimated in this paper. The first form, called 'full form' and expressed in Eq. (1), includes the set of explanatory variables in addition to personal disposable income. The second form, called 'reduced form', includes only the income variable by removing the other explanatory variables in Eq. 1.

The results of model (1) based on the whole regions

The estimates of both the 'full form' and the 'reduced form' expressed in Eq. 1 are listed in Table 2. The regression line covering the whole regions in Table 2 has been fitted with a cubic term of income for the full model with R-square of 0.7576 and for the 'reduced form' with R-square of 0.1943 . These two models seem to be satisfactory since the income variable and other explanatory variables are statistically significant. The result demonstrates that an inverted $\mathrm{N}$-shaped curve exists as the personal income rises for both the two forms of Eq. 1. As personal disposable income increases, per capita MSW waste disposed firstly declines, then grows at the second stage and finally decreases again for the pooled data covering the whole 
regions. All the other explanatory variables including social characteristics and geographical barriers are found to influence MSW disposal significantly. In other words, population density, age composition, unemployment rate and the education level are found significant in determining MSW disposal for the 'full form' of Eq. 1. Each person increase in population density brings about an increase in MSW disposed by approximately $1.17 \times 10^{-4} \mathrm{~kg} /$ person/day. The significantly negative coefficient of the age variable may be attributable to the relatively low consumption of the aged since most of the aged beyond 65 years old prefer to stay at home and some of them incur sickness and require impatient medicare. Each percent increase in age composition leads to a decrease in MSW disposed by approximately $0.0224 \mathrm{~kg} /$ person/day. The jobless may perceive of lower levels of well-being and thus cut down the consumption budget due to future uncertainty. Consequently, MSW generation is accordingly reduced. Each percent increase in unemployment rate reduces MSW disposed of 0.0901 $\mathrm{kg} /$ person/day. The negative coefficient of education levels coincides with the expectation followed in the current study. This paper finds each percent increase in the education level results in a decrease in MSW disposed of $0.01556 \mathrm{~kg} /$ day. Rising education levels may be an effective tool to enhance recycling behaviors, to modify consumption pattern, and eventually to reduce MSW disposal. The dummy variable to identify the location of the region observed is highly significant. This implies that the geographical variation may explain the difference of MSW disposal between urban regions and rural regions.

\section{The comparison of the urban regions with rural regions}

Table 2 also demonstrates that both the urban regions and the rural regions also execute an inverted $\mathrm{N}$ curve for the 'full form' of Eq. 1. Population density and unemployment rate have a significant impact on MSW disposed in the urban regions while population density and age composition play significant roles in rural regions. Each percent increase in age composition reduces MSW disposed by approximately $0.033 \mathrm{~kg} /$ person/day in the rural regions. Each percent increase in unemployment rate brings about a decrease in MSW disposed of $0.137 \mathrm{~kg} /$ person/day.

Population density in the both regions is found to positively affect the EKC curve. Each person increase in population density increase MSW disposed by approximately $1.1 \times 10^{-4} \mathrm{~kg} /$ person/day in urban regions, and $2.1 \times 10^{-3} \mathrm{~kg} /$ person/day in rural regions. In general, urban regions have higher population density and thus require lower cost of service for MSW collection and better waste collecting efficiency. On the contrary, the waste collecting service is not provided for some mountain areas in rural regions as waste collecting trucks cannot arrive. Households living in these isolated mountain areas may throw away household wastes into the surrounding environment. And thus, the change for the MSW disposed is higher for each unit of change in population density in the rural regions. The results of the 'reduced form' in Table 2, however, cannot support the existence of an inverted $\mathrm{N}$-shaped curve in the rural regions, but that of the 'full form' of model (1) can. This result implies that geographical factors and social characteristics are more significant than economic factors to account for the shifting of MSW disposal.

The insufficient evidence to support the inverted $\mathrm{N}$-shaped curve in the rural regions may attribute to its lower income. Rising disposable income may increase the propensity to consume and generate solid wastes, but it also can bring about the increase in recycling rate through rising education levels. Conventional perspectives indicate that wealthy people are concerned more with environmental protection and participate in environmental activities to a larger extent than the poor as environmental attitudes and behaviors have a significantly positive correlation with income (Diekmann and Franzen, 1999; Domino and Koch, 2002). Other researchers, however, refuse to recognize the significant relationship between income and recycling (e.g. Scott, 1999; Do Valle et al., 2004). On the contrary, some researchers reveal that poor people exhibits a higher degree of concern and awareness than the rich (Dunlap et al., 1993; Dunlap and Merit, 1995). Tarrant and Cordell (1997) also find that low-income groups have higher correlation between attitude and behaviors. In reality, a lot of unemployed labors in rural regions are forced to work as a rag picker to collect recyclable wastes and sort them out further. These rag pickers are in general categorized as 'the poor' and may contribute more in the recycling for MSW management practice.

This paper suggests that the EKC phenomenon involving MSW disposal is explained partly by income levels that differ strongly between urban and rural regions, but greatly depends on geographical 
and social factors including population density, age composition, unemployment rate and the education level. Income levels and social characteristics not only affect the consumption level and pattern but also MSW generation and recycling.
The turning points of the inverted $N$-shaped curve

The inverted $\mathrm{N}$-shaped curve can be divided into three stages by two turning points. In order to obtain the two turning points (one is a minimum and the other is a maximum), this research takes the differentiation

Table 1: The descriptive statistics

\begin{tabular}{|c|c|c|c|c|c|c|c|c|}
\hline & \multicolumn{4}{|c|}{ 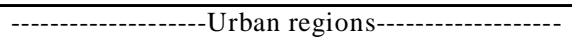 } & \multicolumn{4}{|c|}{ 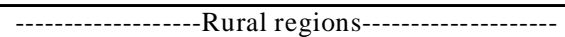 } \\
\hline & Mean & S.D. & Max. & Min. & Mean & S.D. & Max. & Min. \\
\hline$w^{*}$ & 0.7851 & 0.275 & 1.43 & 0.39 & 0.9285 & 0.262 & 1.39 & 0.51 \\
\hline$l^{*}$ & 298988 & 45737 & 392385 & 248757 & 212793 & 19117 & 256628 & 168942 \\
\hline popd* & 8499.8 & 1766 & 9861 & 5615 & 120.494 & 69.11 & 217.29 & 67.12 \\
\hline old $*(\%)$ & 42.31 & 12.55 & 70.5 & 26.2 & 57.5293 & 7.001 & 70.68 & 43.6 \\
\hline unemp $*(\%)$ & 4.1 & 0.84 & 5.5 & 2.6 & 4.2481 & 0.791 & 5.5 & 2.8 \\
\hline$e d u^{*}(\%)$ & 45.3 & 8.807 & 63.47 & 30.41 & 17.89 & 5.57 & 27.63 & 8.69 \\
\hline
\end{tabular}

* $w$ represents MSW disposed, $I$ household disposable income, popd population density, old the composition of old people, unemp unemployment rate, and $e d u$ the education level

Table 2: The estimated results of the pooled data, urban regions and rural regions (standard errors in brackets)

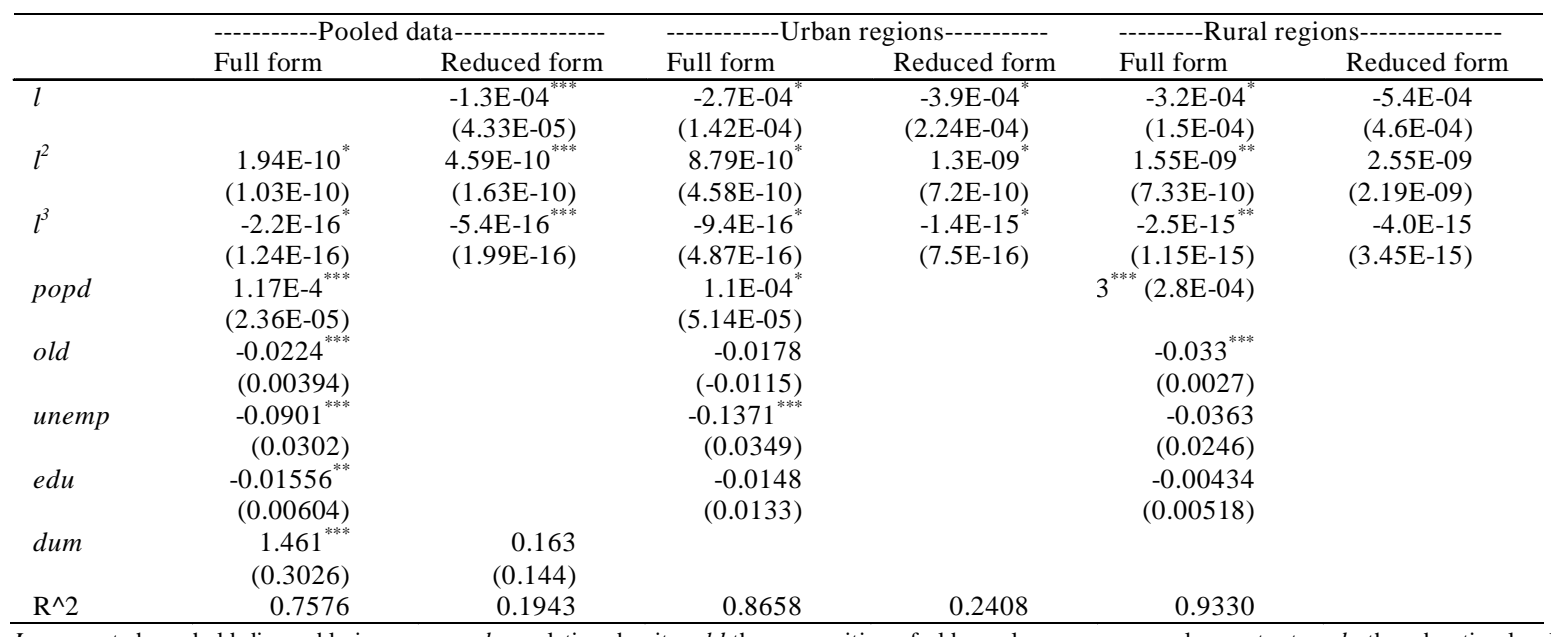

I represents household disposable income, popd population density, old the composition of old people, unemp unemployment rate, edu the education level and dum the dummy variable. * Denotes $90 \%$ confidence level, ** $95 \%$ confidence level and *** $99 \%$ confidence level.

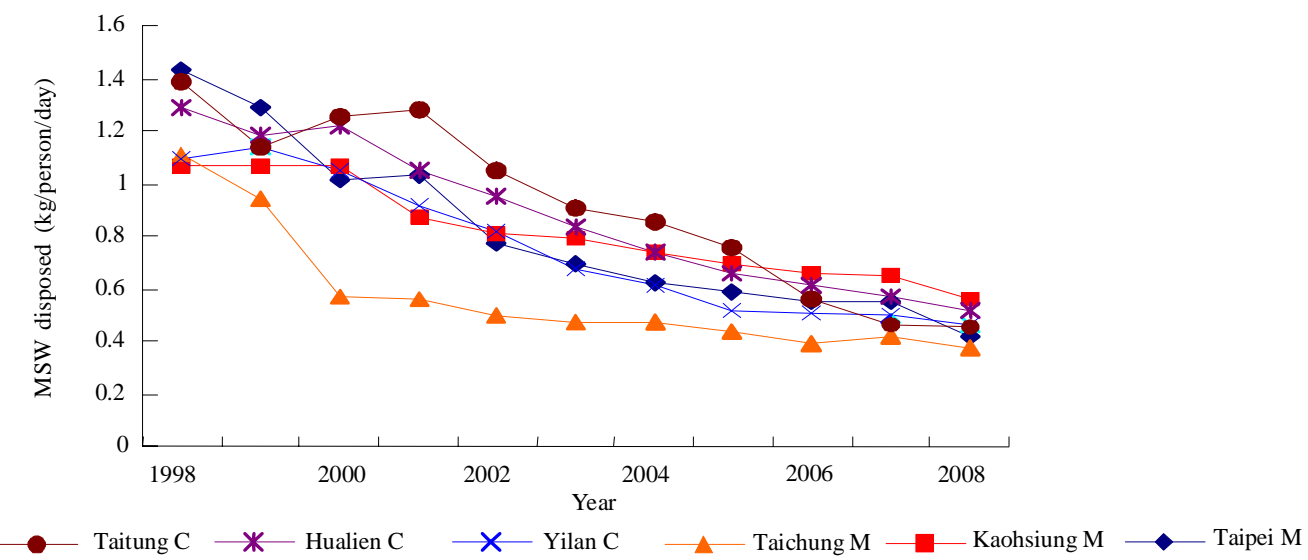

Fig. 2: The MSW disposed in the six regions over 1998-2006 
of Eq. 1 with $I$ and then yields

$\alpha_{1}+2 \alpha_{2} I+3 \alpha_{3} I^{2}=0$

Solving Eq. 7 yields the two turning points occurring at income of

$$
I=\frac{-\alpha_{2} \pm \sqrt{\alpha_{2}^{2}-3 \alpha_{1} \alpha_{3}}}{3 \alpha_{3}}
$$

The value of coefficients, and of the 'full form' in Table 2 is substituted into Eq. 8 and then the first turning point (the minimum) is obtained to occur at the personal disposable income of NT\$198,000 and the second point (the maximum) at NT\$389,000 for the pooled data (covering the six regions). Similarly, the turning point occurs at NT\$274,000 and NT\$349,000 for urban regions and at NT\$200,000 and NT\$213,000 for rural regions. In brief, the estimated turning points lie within the income range of NT\$198,000-274,000 for the first turning point and NT\$213,000-389,000 for the second point for each region in Taiwan. The information about the two turning points demonstrates that MSW disposal exhibits a decreasing pattern for personal disposable income below a critical level (the first turning point). After the first turning point, it exhibits an EKC curve (an inverted U-shaped relationship) where MSW disposal reaches a peak (the second turning point) at a certain income level along the EKC path and declines afterwards with income increasing further.

Based on the estimated results of the inverted Nshaped curve in Table 2, the trend of MSW disposal, generation and recycling along with income is suggested and depicted in Fig. 3. The personal disposable income below the first turning point (the minimum) is labeled as sStage I, where most people are poor, consuming almost all their income on food and necessary goods and living in a relatively bad living condition. Consumption serves basic needs for most people. Thus the waste generation keeps almost the same, unrelated with income, but the recycling rate increases along with income levels. In this stage $\frac{d w_{f}}{d I}=\frac{d w_{g}}{d I}-\frac{d w_{r}}{d I}<0$.

When the personal disposable income falls between the first turning point and the second turning point, it is labeled as stage II. At this stage, the consumption increases and diversifies. The driving force for consumption is shifted from the satisfaction of basic needs to joyful and playful activities for the construction of identities (Firat and Dholakia, 1998). Material consumption is, however, seen as the primary way towards welfare and thus MSW generation rapidly increases in stage II, where $\frac{d w_{f}}{d I}=\frac{d w_{g}}{d I}-\frac{d w_{r}}{d I}>0$, even though recycling rate still keep growing.

After the personal disposable income reaches to the second turning point, it steps into stage III where $=\frac{d w_{f}}{d I}=\frac{d w_{g}}{d I}-\frac{d w_{r}}{d I}>0$. At this stage, consumers tend to shift their consumption pattern from manufacturing products to services. They seek for more spiritual life and shift their consumption pattern from current culture of limitlessly material consumerism to spiritual aspirations. They like to travel to rural regions very

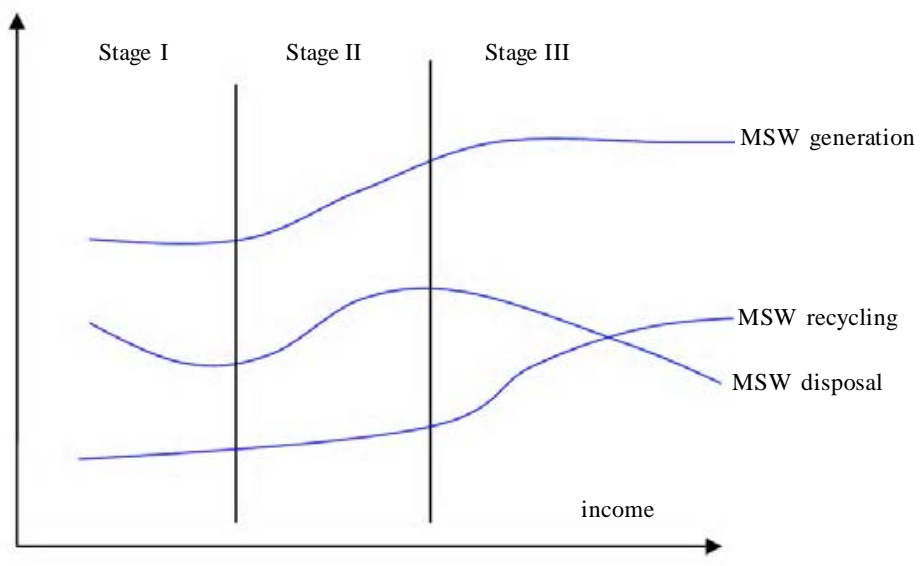

Fig. 3: The inverted N-curve of MSW disposal 
often and consume outside their home. Since service industry yields less pollution, MSW generation does not keep growing. The special features of wealthier people are less consumptive, greater mobility and shorter residence times. Rich people concern more about their well-being and generally have a wider range of options available and a greater capacity to change their consumption pattern. As material welfare does not yield happiness absolutely, the rich prefer to senses of security, clean environment, family ties and friendships, or at least see them as important as material possessions. At this stage, the rich may focus on the pursuit of social status and their value adheres to group norms that attempt to live a sustainable lifestyle featuring recycling, political activism and minimalist consumerism (Sobel, 2005).

The policy implication on Taiwan's MSW disposal

The personal disposable income in urban regions ranges from NT\$248,757 to NT\$392,385(Table 1). All of them are higher than the first turning point (NT\$198,000), falling at Stage II and Stage III of the inverted N-shaped curve (model 1). This demonstrates that urban regions execute an inverted U-shaped pattern of the EKC relationship. In contrast, rural regions falls at either Stage I or II as the personal disposable income (ranged from NT\$ 168,942 to NT\$256,628, Table 1), lower than the second turning point (NT\$398,000). Based on the analysis, a conclusion is made that there exists an inverted U-shaped curve of the EKC relationship between MSW disposal and personal disposable income in urban regions, but there is lacking of evidence to support such a relationship in rural regions. To test whether an inverted U-shaped relationship exists or not, the term of cubic income in Eq. 1 is removed and model (1) becomes

$$
\begin{aligned}
& w_{i t}=\alpha_{0}+\alpha_{1} I_{i t}+\alpha_{2} I_{i t}^{2}+\alpha_{4} \text { popd }_{i t}+\alpha_{5} \text { old }_{i t}+ \\
& \alpha_{6} \text { unemp }_{i t}+\alpha_{7} \text { edu }_{i t}+\alpha_{8} \text { dum }_{i}+\varepsilon_{i t}
\end{aligned}
$$

The estimated results for model (1A) are shown in Table 3. The 'full form' is found to be fitted for the whole regions with $\mathrm{R}$-square of 0.7019 as the square term of the income variable is significant, but the 'reduced form' is rejected. The social characteristics plays an important role in shaping the EKC as the other explanatory variables in addition to the income variable are found to be significant in the 'full form' of model (1A). Each person increase in population density brings about an increase in MSW disposed by approximately $1.25 \times 10^{-4} \mathrm{~kg} /$ person/day. Each percent increase in age composition leads to a decrease in MSW disposed by approximately $0.0227 \mathrm{~kg} /$ person/day, in unemployment rate a decrease in MSW disposed of $0.107 \mathrm{~kg} /$ person/day, in the education level a decrease in MSW disposed of $0.0148 \mathrm{~kg} /$ day. The estimated result in Table 3, however, also demonstrates that the existence of an inverted U-shaped curve cannot be supported by the income variable only for whole regions.

When the test is conducted on each group of data, this paper finds that an inverted U-shaped curve significantly exists by the 'reduced form' of model (1A) under $90 \%$ confidence level in urban regions. The turning point lies at personal disposable income NT\$ 313,500 in urban regions where the turning point is calculated and obtained by substituting the value of $\alpha_{1}$ and $\alpha_{2}$ in Table 3 into the formula of $I=\frac{-\alpha_{1}}{2 \alpha_{2}}$.

\begin{tabular}{|c|c|c|c|c|c|c|}
\hline & \multicolumn{2}{|l|}{ Pooled data } & \multicolumn{2}{|l|}{ Urban regions } & \multicolumn{2}{|l|}{ Rural regions } \\
\hline & Model A & Model B & Model A & Model B & Model A & Model B \\
\hline \multirow[t]{2}{*}{$I$} & $-4.5 \mathrm{E}-06$ & $-9.3 E-06$ & $4.02 \mathrm{E}-06$ & $3.7 \mathrm{E}-05^{*}$ & $9.6 \mathrm{E}-06$ & $-6.8 \mathrm{E}-06$ \\
\hline & (4.69E-06) & $(7.94 \mathrm{E}-06)$ & (1.08E-05) & $(2.24 \mathrm{E}-04)$ & $(1.4 \mathrm{E}-05)$ & (3.68E-05) \\
\hline \multirow{2}{*}{$I^{2}$} & $1.57 \mathrm{E}-11^{*}$ & $1.46 \mathrm{E}-11$ & $-4.3 \mathrm{E}-13$ & $-5.9 \mathrm{E}-11^{*}$ & $-2.2 \mathrm{E}-11$ & $2.77 \mathrm{E}-12$ \\
\hline & (1.03E-10) & $(1.31 \mathrm{E}-11)$ & (1.73E-11) & (3.33E-11) & (3.35E-11) & (8.7E-11) \\
\hline \multirow[t]{2}{*}{ popd } & $1.25 \mathrm{E}-4^{* * * *}$ & & $1.74 \mathrm{E}-04^{* * *}$ & & $-0.00216^{* * *}$ & \\
\hline & $(2.37 \mathrm{E}-05)$ & & (3.98E-05) & & $(0.00031)$ & \\
\hline \multirow[t]{2}{*}{ old } & $-0.0227^{* * * *}$ & & $-0.0318^{* * *}$ & & $-0.033^{* * *}$ & \\
\hline & $(0.00402)$ & & $(-0.00946)$ & & $(0.002933)$ & \\
\hline \multirow[t]{2}{*}{ unemp } & $-0.1074^{* * *}$ & & $-0.1602^{* * *}$ & & $-0.0495^{*}$ & \\
\hline & $(0.0292)$ & & $(0.0349)$ & & (0.0259) & \\
\hline \multirow[t]{2}{*}{ Edu } & $-0.01487^{* *}$ & & -0.00248 & & -0.00281 & \\
\hline & $(0.00616)$ & & $(0.0138)$ & & $(0.00557)$ & \\
\hline \multirow[t]{2}{*}{ dum } & $1.474^{* * *}$ & 0.01126 & & & & \\
\hline & (0.309) & $(0.141)$ & & & & \\
\hline $\mathrm{R}^{\wedge} 2$ & 0.7019 & 0.0956 & 0.8419 & 0.1185 & 0.9167 & 0.1663 \\
\hline
\end{tabular}

Table 3: The estimated results of the pooled data, urban regions and rural regions (standard errors in brackets)

I represents household disposable income, popd population density, old the composition of old people, unemp unemployment rate, edu the education level and dum the dummy variable. * Denotes $90 \%$ confidence level, ** $95 \%$ confidence level and *** $99 \%$ confidence level. 
The MSW disposed in urban regions increases as personal disposable income increases, and then starts declining after the maximum point of personal disposable income (NT\$313,500). As personal disposable income moves beyond the turning point (at NT\$ 313,500), a natural force will push MSW disposal decreasing to improve environmental quality. In other words, the economic development may play a self-regulation role in affecting the urban regions towards a clean economy.

In contrast, the inverted U-shaped curve does not receive the significant support in the rural regions (Table 3). This result implies that the income level has not yet reached to a point that can support the rural regions to follow the path of an inverted U-shaped relationship for MSW disposal. And thus, economic growth may be associated with worsening MSW disposal for the poor regions. It may be a solution to improve MSW disposal in the rural regions by investing more on improving social status such as the education level, age composition, unemployment rate, etc.

\section{CONCLUSION}

This research incorporates economic, social, and geographical factors into the model to explain the variation in MSW disposal in Taiwan and find that there are distinctive and often growing differences in MSW disposal between urban and rural regions. This study verifies that both the urban regions and rural regions follow the inverted-N-shaped curve but the location of the turning points may vary across regions as per their economic position and social status. The results demonstrate that income can explain a portion of variation only and the other social and geographical factors contribute more and thus these factors cannot be ignored in the process of policy making. In reality many factors influence the waste generation and recycling such as economic and demographic developments, technological change, resource endowments, institutional frameworks, and lifestyles.

This investigation makes a useful contribution to the research on the existence of an inverted N-shaped EKC for MSW disposal and the results derived from this paper challenges a number of important assumptions. As the inverted-N-shaped curve exists for MSW disposal covering the whole regions, the prospect is optimistic to improve environmental quality. MSW disposal will automatically lead to eventually environmental improvement through decreased MSW generation and increased recycling along with economic growth when income levels attain to the turning point.
The automatic remedy for MSW disposal through economic development depends not only on recycling behaviors but also on green consumption and levels of consumption. Household behaviors are critical to the successful attainment of desired targets for MSW management practice. The results derived in this research suggest that MSW management should be interdisciplinary by integrating socioeconomic, environmental, and technological aspects. And thus, the aims and actions derived from environmental policy are required to comply with more integrated and sustainable waste management solutions. Only all the parties are integrated and effectively involve in this apparent culture change, sustainable MSW management may be successful. The examination on the EKC curve across various regions can be helpful to find out the regional current status of sustainable development and the information of the results can provide some valuable corresponding countermeasures to MSW management towards a sustainable society.

\section{ACKNOWLEDGEMENTS}

The author is grateful to anonymous referees for the valuable comments and the Editor for his suggestion on an earlier version of this research. In addition, the author is also grateful to National Science Council (Taiwan) for its financial support under contract No.: NSC 96-2416-H-343-001-MY2, entitled “The efficiency evaluation on utility services and privatization study in consideration of policy objectives”.

\section{REFERENCES}

Bamberg, S., (2003). How does environmental concern influence specific environmentally related behaviors? A new answer to an old question. J. Environ. Psycho., 23 (1), 21-32 (12 pages).

Bell, A. P.; Greene, T. C.; Fisher, J. D.; Baum, A., (2001). Environmental psychology. $5^{\text {th }}$ Ed., Orlando, F. L., Harcourt College Publishers.

Bickerstaff, K.; Walker, G., (2001). Public understandings of air pollution: the 'localisation' of environmental risk. Global Environ. Chang., 11 (2), 133-145 (13 pages).

Copeland, B. R.; Taylor, M. S., (2004). Trade, growth and the environment. J. Econ. Lit., 42 (1), 7-71 (65 pages).

DGBAS, (2008). http://61.60.106.82/pxweb/Dialog/statfile9. asp.

Diekmann, A.; Franzen, A., (1999). The wealth of nations and environmental concern. Environ. Behav., 31 (4), 540-549 (10 pages).

Dinda, S., (2004). Environmental Kuznets Curve hypothesis: A survey. Eco. Econ., 49 (2), 431-455 (25 pages).

Domina, T.; Koch, K., (2002). Convenience and frequency of recycling: Implications for including textiles in curbside recycling 
programs. Environ. Behav., 34 (2), 216-238 (25 pages).

Do Valle, P. O.; Reis, E.; Menezes, J.; Rebelo, E., (2004). Behavioral determinants of household recycling participation. Environ. Behav., 36 (4), 505-540 (34 pages).

Dunlap, R. E.; Gallup, J. G. H.; Gallup, A. M., (1993). Of global concern: Results of the health of the planet survey. Environment, 35 (9), 6-17 (12 pages).

Dunlap, R. E.; Mertig, A. G., (1995). Global concern for the environment: Is affluence a prerequisite? J. Soc. Issues, 51 (4), 122-137 (16 pages).

Ebreo, A.; Hershey, J.; Vining, J., (1999). Reducing solid waste: Linking recycling to environmentally responsible consumerism. Environ. Behav., 31 (1), 107-135 (29 pages).

Ewing, G., (2001). Altruistic, egoistic, and normative effects on curbside recycling. Environ. Behav., 33 (6), 733-764 (32 pages).

Firat, A. F.; Dholakia, N., (1998). Consuming people. From political economy to theaters of consumption. Routledge, London.

Friedl, B.; Getzner, M., (2003). Determinants of $\mathrm{CO}_{2}$ emissions in a small open economy. Eco. Econ., 45 (1), 133-148 (16 pages).

Galeotti, M.; Lanza, A., (2005). Desperately seeking environmental Kuznets. Environ. Model. Softw., 20 (11), 1379-1388 (10 pages).

Harbaugh, W. T.; Levinson, A.; Wilson, D. M., (2002). Reexamining the empirical evidence for an environmental Kuznets Curve. Rev. Econ. Stat., 84 (3), 541-551 (11 pages).

Iwata, O., (2002). Coping style and three psychological measures associated with environmentally responsible behavior. Soc. Behav. Personal., 30 (7), 661-669 (9 pages).

Kahn, M. E., (1998). A household level environmental Kuznets Curve. Econ. Lett., 59 (2), 269-273 (5 pages).

Kearsley, A.; Riddel, M., (2010). A further inquiry into the Pollution Haven Hypothesis and the Environmental Kuznets Curve. Ecol. Econ., 69 (4), 905-919 (15 pages).

Koop, G.; Tole, L., (1999). Is there an environmental Kuznets curve for deforestation? J. Develop. Econ., 58 (1), 231-244 (14 pages).

Kotchen, M.; Moore, M., (2007). Private provision of environmental public goods: Household participation in greenelectricity programs. J. Environ. Econ. Manage., 53 (1), 116 (16 pages).

Mattson, C.; Berg, P. E. O.; Clarkson, P., (2003). The development of systems for property close collection of recyclables: Experiences from Sweden and England. Resour. Conserv. Recycl., 38 (1), 39-57 (19 pages).

McDonald, S.; Oates, C., (2003). Reasons for non-participation in a kerbside recycling scheme. Resour. Conserv. Recycl., 39 (4), 369-385 (27 pages).

Merlevede, B.; Verbeke, Y.; De Clercq, M., (2006). The EKC for $\mathrm{SO}_{2}$ : Does firm size matter? Ecol. Econ., 59 (4), 451-461
(11 pages).

Ogundiran, O. O.; Afolabi, T. A., (2008). Assessment of the physicochemical parameters and heavy metals' toxicity of leachates from municipal solid waste open dumpsite. Int. J. Environ. Sci. Tech., 5 (2), 243-250 (8 pages).

Pattnaik, S.; Reddy, M. V., (2010). Assessment of municipal solid waste management in Puducherry (Pondicherry), India. Resour. Conserv. Recycl., 54 (8), 512-520 (9 pages).

Ropke, I., (1999). The dynamics of willingness to consume. Ecol. Econ., 28 (3), 399-420 (22 pages).

Salhofer, S.; Isaac, N., (2002). Importance of public relations in recycling strategies: Principles and case studies. Environ. Manage., 30 (1), 68-76 (9 pages).

Scott D., (1999). Equal opportunity, unequal results: Determinants of household recycling intensity. Environ. Behav., 31 (2), 267-290 (24 pages).

Skonhoft, A.; Solem, H., (2001). Economic growth and landuse changes: The declining amount of wilderness land in Norway. Ecol. Econ., 37 (2), 289-301 (13 pages).

Sobel, J., (2005). Interdependent preferences and reciprocity. J. Econ. Lit., 43 (2), 392-436 (45 pages).

Stern, D. I.; Common, M. S., (2001). Is there an environmental Kuznets Curve for sulphur? J. Environ. Econ. Manage., 41 (2), 162-178 (17 pages).

Tarrant, M. A.; Cordell, H. K., (1997). The effect of respondent characteristics on general environmental attitude-behavior correspondence. Environ. Behav., 29 (5), 618-637 (20 pages).

Teisl, M. F.; Roe, B.; Hicks, R. L., (2002). Can eco-labels tune a market? Evidence from dolphin-safe labeling. J. Environ. Econ. Manage., 43 (3), 339-359 (21 pages).

Tonglet, M.; Phillips, P. S.; Read, A. D., (2004). Using the theory of planned behaviour to investigate the determinants of recycling behaviour: A case study from Brixworth, UK. Resour. Conserv. Recycl., 41 (3), 191-214 (24 pages).

Torras, M.; Boyce, J. K., (1998). Income, inequality and pollution: A reassessment of the environmental Kuznets curve. Ecol. Econ., 25 (2), 147-160 (14 pages).

Vinodhini, R.; Narayanan, M., (2008). Bioaccumulation of heavy metals in organs of fresh water fish Cyprinus carpio (Common carp). Int. J. Environ. Sci. Tech., 5 (2), 179-182 (4 pages).

Werner, C. M.; Makela, E., (1998). Motivations and behaviors that support recycling. J. Environ. Psychol., 18 (4), 373386 (14 pages).

Williams, I. D.; Kelly, J., (2003). Greenwaste collection and the public's recycling behaviour in the Borough of Wyre, England. Resour. Conserv. Recycl., 38 (2), 139-159 (21 pages).

Zaman, A. U., (2010). Comparative study of municipal solid waste treatment technologies using life cycle assessment method. Int. J. Environ. Sci. Tech., 7 (2), 225-234 (10 pages).

\section{AUTHOR (S) BIOSKETCHES}

Chen, C. C., Ph.D., Full Processor, Graduate Institute of Environmental Management, Nanhua University and Dean of Management College of Nanhua University, Taiwan. At present, He is the founding Editor and Editor-in-Chief of Journal of Environment and Management. Email: ccchen@mail.nhu.edu.tw 